\title{
Vivências do Centro da Criança e do Adolescente do Hospital CUF Descobertas Durante a Pandemia COVID-19
}

\section{Centre for Children and Adolescents of Hospital CUF Descobertas: Experiences During the COVID-19 Pandemic}

Hugo de Castro Fariaª , Mónica Cró Braz², Ana Serrão Neto³

Autor Correspondente/Corresponding Author: Hugo Castro Faria [hugo.faria@jmellosaude.pt]

R. Mário Botas, 1998-018 Lisboa, Portugal

ORCID ID: 0000-0001-9250-2734

\section{RESUMO}

A pandemia de COVID-19 obrigou toda a sociedade portuguesa a um esforço de reorganização e preparação para contenção e mitigação do vírus. O Centro da Criança e do Adolescente do Hospital CUF Descobertas não foi exceção. Foi necessário adaptar o serviço por forma a dar resposta a situações urgentes garantindo qualidade de cuidados e prevenção do contágio entre doentes e profissionais.

Neste artigo os autores descrevem todo o processo de adaptação que obrigou, num curto espaço de tempo, a repensar espaços, circuitos, protocolos e procedimentos, equipamentos de proteção individual, integração de novos elementos na equipa em condições difíceis do ponto de vista de gestão e liderança de equipas.

A implementação de um gabinete de crise ágil e empenhado foi fundamental para assegurar liderança forte e assertiva ao longo de toda a evolução.

PALAVRAS-CHAVE: COVID-19; Infeções por Coronavírus; Pandemia; Pediatria/organização e administração; Pessoal de Saúde

1. Pediatra Centro da Criança e do Adolescente, Hospital CUF Descobertas, Responsável do Atendimento Permanente de Pediatria, Lisboa, Portugal. 2. Pediatra Centro da Criança e do Adolescente, Hospital CUF Descobertas, Membro do Grupo de Coordenação Local, Programa de Prevenção e Controlo de Infeções e Resistência aos Antimicrobianos (GCL-PPCIRA) do Hospital CUF Descobertas, Lisboa, Portugal. 3. Pediatra, Coordenadora Centro da Criança e do Adolescente do Hospital CUF Descobertas, Lisboa, Portugal.

Recebido/Received: 25/05/2020 - Aceite/Accepted: 06/06/2020 - Publicado/Published: 30/06/2020

${ }^{0}$ Autor (es) (ou seu (s) empregador (es)) 2020. Reutilização permitida de acordo com CC BY-NC. Nenhuma reutilização comercial. ${ }^{\bullet}$ Author(s) (or their employer(s)) 2020. Re-use permitted under CC BY-NC. No commercial re-use. 


\section{ABSTRACT}

The COVID-19 pandemic forced the Portuguese society into an effort to reorganize and prepare for the containment and mitigation of the virus. The Centre for Children and Adolescents of Hospital CUF Descobertas was no exception. It was necessary to adapt the department in order to respond to emergent situations, ensuring quality of care and prevention of contagion between patients and healthcare workers.

In this article, the authors describe the entire adaptation process that forced, in a short period of time, to rethink spaces, circuits, protocols, procedures, personal protective equipment, integration of new elements in the team, in difficult conditions, from the point of view of management and team leadership.

The implementation of an agile and committed crisis office was instrumental in ensuring strong and assertive leadership throughout the evolution.

KEYWORDS: Coronavirus Infections; COVID-19; Health Personnel; Pandemics; Pediatrics/organization \& administration

\section{INTRODUÇÃO}

A atual pandemia obrigou-nos a todos, médicos, enfermeiros, gestores e administradores, a um esforço de reorganização dos serviços por forma a continuarmos a prestar cuidados de saúde com segurança a todo o tipo de doentes. Todos nós éramos inexperientes, ninguém tinha vivenciado uma situação semelhante. Já tínhamos trabalhado, e vivido, sob epidemias, mas nunca sob uma pandemia que obrigou o nosso mundo a parar.1,2

Sobre o vírus, muito já se escreveu e disse, e muitas das afirmações ainda estão por provar. Quando nos pediram para escrevermos para um número da Gazeta Médica dedicado à pandemia causada pelo novo coronavírus (COVID-19) achámos que não teríamos muito a acrescentar sobre a ciência do vírus. Portanto, entendemos que seria mais interessante partilharmos com os leitores a experiência da adaptação do nosso serviço de pediatria, o Centro da Criança e do Adolescente, integrado num hospital generalista, o Hospital CUF Descobertas (HCD).

A José de Mello Saúde (JMS) definiu uma orientação estratégica da qual resultou que o HCD seria um hospital COVID free, sobretudo com o objetivo de proteger a maternidade e a oncologia.

Assim sendo, e por ter sido prevista a colaboração com o Serviço Nacional de Saúde (SNS), ${ }^{3}$ foi decidido o HCD encerrar ao público o Atendimento Permanente de Adultos e deslocalizar o Atendimento Permanente Pediátrico e o de Ginecologia Obstetrícia para um local onde a circulação do fluxo de ar pudesse ser segregada do resto do hospital.

O Atendimento Permanente de Adultos aberto ao público ficou sediado no Hospital CUF Infante Santo, onde os doentes COVID seriam hospitalizados. Os doentes não COVID que necessitassem de cuidados urgentes e/ou internamento seriam referenciados para o Atendimento Permanente de Adultos do HCD, cuja equipa se mantinha em urgência interna.

A CUF encerrou todos os Atendimentos Permanentes de Pediatria (APP) da Área Metropolitana de Lisboa e centralizou as equipas clínicas e todos os cuidados de saúde no HCD. No local temporário do APP foi necessário garantir dois circuitos separados, uma vez que tanto poderíamos observar doentes COVID, como doentes não COVID. Apenas se referenciava para o Hospital de Dona Estefânia (HDE) os doentes positivos que carecessem de hospitalização.

O Atendimento Permanente (AP) de Ginecologia Obstetrícia também mudou de local e garantiu dois circuitos separados para acautelar o risco infecioso. No edifício 2 organizou-se o AP e o bloco de partos para casos suspeitos ou positivos. Para o edifício 1 apenas seguiam as grávidas negativas. Apesar de estar prevista a transferência de grávidas COVID positivas para a rede pública, era preciso prever um parto emergente.

Em suma, preparámo-nos a meio de março para o pior, pois já era conhecida a situação de Itália e Espanha, e numa semana reinventámos os circuitos de doentes e de colaboradores do HCD para darmos segurança a todos. É a experiência do Centro da Criança e do Adolescente que vamos partilhar convosco, desde as alterações do espaço físico até à reorganização das equipas clínicas, passando pelas exigências implícitas, como elaboração de protocolos de atuação específicos, gestão de stress e liderança de equipas. 


\section{COVID-19 NO HCD}

A 18 de março foi declarado o Estado de emergência em Portugal. Nesse mesmo dia, no HCD foi possível delinear um plano de contingência porque, uns dias antes, a JMS já tinha criado um gabinete de crise transversal às unidades CUF.

No HCD, o plano de contingência e o gabinete de crise local envolveu elementos da Administração, Direção da Qualidade e Segurança (DQS), Programa de Prevenção e Controlo de Infeções e Resistência aos Antimicrobianos (PPCIRA), Direção Clínica, Coordenadores Clínicos e Responsáveis pelos Atendimentos Permanentes de Adultos, Pediatria e Ginecologia-Obstetrícia.

Foram tomadas medidas para minimizar a transmissão de COVID-19 entre doentes, entre profissionais de saúde e entre doentes e profissionais de saúde, por forma a limitar a aquisição de infeções associadas a cuidados de saúde. O objetivo era reduzir o risco da CUF funcionar como amplificador da COVID-19, tendo em consideração que, de acordo com os estudos internacionais, 20\% dos doentes infetados são profissionais de saúde. ${ }^{4,5}$

Deste modo, era necessário garantir:

- Atendimentos Permanentes em locais com circulação de ar segregável, para que não houvesse contaminação de ar no hospital que se pretendia COVID free;

- Prestação de cuidados de saúde em segurança a casos suspeitos pelo uso de equipamentos de proteção individual (EPI) adequados a cada procedimento, além da correta higienização das mãos e das regras de etiqueta respiratória consoante se prestavam cuidados não invasivos ou invasivos ${ }^{6}$;

- Medidas de descontaminação de superfícies e de objetos e medidas de controlo ambiental;

- Minimização de contágio de doentes que procuram a urgência sem suspeita de COVID-19;

- Identificação rápida de casos suspeitos e isolamento dos mesmos durante o período necessário à prestação de cuidados;

- Identificação rápida de casos positivos e de possíveis contactos na instituição, com outros doentes e profissionais de saúde, e respetiva classificação em alto e baixo risco de aquisição da doença;

- Vigilância epidemiológica ativa de contactos em profissionais de saúde, pela saúde ocupacional.

\section{COVID-19 NO APP DO HCD}

A nova realidade exigia uma urgência pediátrica que conseguisse assegurar cuidados adequados a situações urgentes garantindo segurança perante o risco infecioso para doentes e profissionais. Era necessário termos condições para observar e diagnosticar todos os doentes, já que no HCD funcionaria a única urgência pediátrica CUF.

O plano de contingência da Direção-Geral da Saúde $(D G S)^{3}$ previa que crianças com COVID-19 e necessidade de internamento fossem transferidas para o SNS, mas tínhamos de garantir cuidados e internamento adequado até ao resultado do teste, feito por PCR em tempo real que, no limite, poderia demorar 24 horas. Como o HCD era hospital não COVID, a necessidade de correta identificação dos doentes era ainda mais imperiosa, porque tínhamos de continuar a internar todos os doentes não COVID em igual segurança.

Como base de trabalho utilizámos as recomendações da Associação Espanhola de Pediatria (AEPED). ${ }^{7}$ Espanha estava em fase mais avançada da pandemia, pelo que tinha maior experiência e tinha elaborado muita bibliografia. Por outro lado, o contacto com colegas espanhóis foi tranquilizador, pois confirmámos que a doença seria maioritariamente ligeira nas crianças e que a habitual afluência às urgências tinha reduzido significativamente.

O APP existente não oferecia condições para adequada separação de circuitos e havia a indicação para não expor o edifício 1 a doentes com COVID-19, com o objetivo de proteger a maternidade e o hospital de dia oncológico. O sistema de ventilação do edifício 1 não permitia a conveniente segregação do ar. Tendo todas estas premissas em mente, foi escolhido o piso - 1 do edifício 2 como local ideal para montar a nova urgência de pediatria e de Ginecologia-Obstetrícia. Estas decisões foram tomadas no dia 18 de março, e no dia 23 o APP estava a funcionar em pleno no novo espaço, sem nunca ter havido interrupção no atendimento de doentes.

Este piso dispunha de uma entrada direta para a rua através de uma saída de emergência, as dimensões do espaço permitiam separação de circuitos, as características da ventilação garantiam duas zonas separadas, havia salas equipadas com fonte de oxigénio, vácuo e ar comprimido em quantidade adequada, salas com capacidade para isolamento de contacto de curta duração.

Planeámos uma urgência com pré-triagem na porta de admissão que, de acordo com a presença ou não de febre e/ou sintomas respiratórios, alocava os doentes 
em dois circuitos totalmente separados: "infecioso" e "não suspeito de COVID". Cada circuito tinha admissão, triagem, salas de espera, gabinetes de observação médica, salas de tratamento e Unidade de Internamento de Curta Duração totalmente separados. Todos os profissionais usavam EPI adequados aos respetivos circuitos de doentes. A sala de reanimação, localizada à entrada, era única, mas estava protocolado que qualquer doente a reanimar seria tratado como potencial doente COVID-19.

De forma a isolar precocemente doentes com risco acrescido de estarem infetados com COVID-19, foi implementado um sistema fast track na triagem do circuito infecioso. Este sistema foi sendo atualizado com a evolução epidemiológica da pandemia. Inicialmente eram isolados apenas doentes com história de viagem a países com transmissão comunitária ativa. Mas, com a constatação de transmissão comunitária em Portugal, este critério desapareceu, passando a ser isolados de imediato os doentes com história de contacto com casos confirmados ou suspeitos, filhos de profissionais de saúde e de agentes de segurança.

O novo espaço do APP contava com equipamento de radiologia convencional próprio e isso permitiu evitar contacto dos doentes com o restante hospital. Apesar deste local ser comum a todas as crianças do APP, os circuitos de acesso eram totalmente separados. A existência de ecógrafo no APP permitiu que exames ecográficos fossem também efetuados neste espaço. Apenas exames de tomografia computorizada (TC) ou ressonância magnética (RM), raramente usados no APP, exigiam a deslocação das crianças ao Serviço de Imagiologia.

De referir ainda que o piso de internamento habitual da pediatria também foi deslocalizado, do piso 4 para o piso 7 do edifício 1, por este garantir uma extração de ar que minorava o risco infecioso. Apesar de só serem hospitalizados crianças, ou adolescentes, depois de sabermos que os testes eram negativos, uma percentagem significativa de resultados são falsos negativos. ${ }^{8}$

A preocupação com o risco de contágio obrigou à adaptação de alguns protocolos clínicos nomeadamente, a evicção de terapêutica nebulizada. A colheita de amostras de secreções respiratórias para testes rápidos também foi minimizada, nomeadamente a pesquisa de antigénio de Streptococcus do grupo A ou a pesquisa de vírus respiratórios. Sempre que esta necessidade se impunha as colheitas eram feitas com EPI completos e precauções máximas.

Os protocolos de suporte básico de vida e de suporte avançado de vida foram igualmente revistos, de acordo com as recomendações atualizadas da American Heart Association e o European Resuscitation Council. ${ }^{9} \mathrm{Ou}$ seja, além de qualquer reanimação exigir que médicos e enfermeiros usassem EPI, foram modificadas algumas manobras.

As adaptações à evolução da pandemia e aos diferentes protocolos e orientações que iam sendo divulgados, tanto pela DGS como pela DQS e PPCIRA, foram constantes e exigiam à equipa um esforço continuado de atualização, articulação e comunicação. 6,10

Por exemplo, a definição de casos suspeitos COVID-19 ia mudando, bem como as normas de proteção individual e a colheita para testes, que começou por ser apenas na nasofaringe e depois simultaneamente na naso e na orofaringe. Aconteceu também existirem divergências entre a DQS e a PPCIRA, que foram sendo ultrapassadas nas reuniões frequentes. É justo salientar a assertividade e a celeridade da esmagadora maioria das decisões tomadas.

Desde o início da pandemia, realizámos 250 colheitas para pesquisa PCR SARS-CoV-2, tendo obtido 4 resultados positivos. Todos os casos positivos corresponderam a crianças sem critério de internamento, que tiveram alta para o domicílio. Para garantir o correto isolamento e tratamento no domicílio foi implementado um sistema de controlo interno de todas as colheitas, além do sistema nacional de notificação da DGS. Um pediatra do serviço acedia ao resultado do teste e informava familiares do doente no mais curto espaço de tempo possível. Os casos positivos foram acompanhados diariamente por telefone até haver confirmação da transferência efetiva do caso para as autoridades de saúde.

\section{A EQUIPA}

O APP do HCD funciona 24 horas por dia todos os dias do ano e é assegurado por uma equipa de pediatras residentes, coadjuvada por alguns prestadores de serviço. As equipas são constituídas por 3, 4 ou 5 elementos consoante a época do ano e o período do dia. Entre a 1 hora e as 9 horas a equipa reduz para dois pediatras. Habitualmente contamos com 19 a 25 médicos.

Com o encerramento de todos os outros APP CUF da Área Metropolitana de Lisboa, as respetivas equipas, num total de 41 médicos, vieram reforçar o APP do HCD.

De repente, tínhamos um conjunto de 60 médicos a trabalhar no HCD, mas muitas incertezas. Pela experiência dos outros países, esperávamos uma redução do número global de doentes, mas não sabíamos se tería- 
mos muitos doentes COVID positivos e, sobretudo, não sabíamos se os pediatras iriam adoecer. Efetivamente a redução do número de doentes durante o período de confinamento foi de 77\%: a média de doentes dia foi de 24,2, enquanto que no período homólogo de 2019 foi de 105 doentes/dia.

Constituímos equipas de 4 médicos, 2 em cada circuito, pela necessidade de separação de circuitos conforme já descrito. A escala de urgência foi programada sempre com dois elementos suplentes que seriam contactados em caso de doença, teste positivo de algum colega ou colega em quarentena. Importa frisar que a equipa residente recebeu colegas num espaço também desconhecido para si, o que implicou ainda mais resiliência e ajustamento.

Uma das maiores preocupações da Coordenação do Centro da Criança foi proporcionar um bom acolhimento aos colegas das outras unidades. Alguns conheciam-se previamente, mas poucos conheciam o HCD, e fazer colegas exteriores sentirem-se em casa é essencial para o funcionamento de uma equipa de urgência. Assim, foi feito um telefonema pessoal para todos os colegas que viriam colaborar, estimulando a colaboração, dando informações necessárias a quem não conhecia o hospital, solicitando a leitura frequente dos e-mails e afirmando o esforço que faríamos para a boa integração das pessoas. Em simultâneo, recordou-se aos colegas residentes do HCD as vantagens de proporcionar um bom acolhimento aos colegas externos. Houve também a preocupação de manter uma boa comunicação com os coordenadores das equipas externas, solicitando informação mais personalizada e confiança às respetivas equipas.

Por outro lado, era necessário informar todos os colaboradores sobre o circuito físico do APP, dos protocolos emanados da DQS e da PPCIRA, para além dos protocolos clínicos em vigor no HCD. Foi inclusive desenhado um croqui de todo o espaço, o qual foi enviado por e-mail aos colegas. Como estávamos impedidos de reunir presencialmente, toda a informação era veiculada por e-mail, mas sabíamos que a leitura de mails não era universal. Portanto, uma das maiores dificuldades foi transmitir as informações necessárias a todos em tempo útil. Ao longo da leitura deste artigo perceberam que a informação era abundante e mudava diariamente, por vezes da manhã para a tarde.

Com o passar dos dias, habituámo-nos a novas formas de comunicação e discussão. Reuniões em espaços amplos, com número limitado de pessoas, utilização de e-mail, videoconferência e grupos de WhatsApp passaram a fazer parte das nossas rotinas e a desempenharem um papel fundamental no desenrolar dos acontecimentos. Mas para uma equipa habituada a reunir diariamente para discussão dos doentes gerou-se uma sensação de isolamento.

Era também necessário saber das condições contratuais de cada um dos médicos por forma a escalarmos as pessoas de acordo com os seus horários e com o objetivo de evitarmos horas extraordinárias. Atendendo à diversidade de situações contratuais não foi tarefa fácil. Uma pediatra do HCD centralizou todas as condições contratuais num ficheiro. Foi a forma mais eficaz de nós próprios termos a informação atualizada e a tempo de elaborarmos a escala de urgência.

Por outro lado, a Direção do hospital convocava-nos para diversas reuniões em vídeo. Era fundamental manter uma articulação estreita, garantir que as diretrizes eram implementadas e que todos os atores envolvidos possuíam o mesmo nível de informação.

Do ponto de vista da liderança da equipa queremos salientar a gestão de stress. Era uma situação desconhecida para todos, geradora de incertezas e algum medo e preocupação com as famílias, também insegurança das normas, nomeadamente de proteção. Por todos estes aspetos, era importante haver uma liderança forte, mas envolver as pessoas para que todos sentissem que participavam nas decisões. Havia muitas decisões a tomar, e rapidamente, mas era preciso não haver precipitações, pensar antes de decidir. A opção foi criar um núcleo decisor de três pessoas: a coordenadora do Centro da Criança e do Adolescente, o responsável do APP e a pediatra da PPCIRA do HCD. Desta forma íamos chegando parcelarmente a mais colegas, mas a forma transversal de comunicar era, como se referiu, por e-mail ou WhatsApp, o que acarretou algumas falhas de comunicação. Por outro lado, os e-mails de grupo podem gerar respostas em cadeia que são desestabilizadoras. Mesmo após as decisões estarem tomadas é preciso prever fatores laterais e gerir possíveis questões de elementos da equipa, tanto de caráter operacional como de discordância pessoal, que inevitavelmente consomem tempo e energia.

Em resumo, em circunstâncias difíceis é assertivo adotar um estilo de liderança mais forte, criar um núcleo decisor central, mas ouvir mais pessoas. ${ }^{11} \mathrm{O}$ objetivo principal é manter a equipa unida, resiliente e motivada. 


\section{AGRADECIMENTOS / ACKNOWLEDGEMENTS}

À Claudia Piek pela disponibilidade com que fez a revisão deste texto.

\section{RESPONSABILIDADES ÉTICAS}

CONFLITOS DE INTERESSE: Os autores declaram a inexistência de conflitos de interesse na realização do presente trabalho.

SUPORTE FINANCEIRO: O presente trabalho não foi suportado por nenhum subsídio ou bolsa.

PROVENIÊNCIA E REVISÃO POR PARES: Não comissionado; revisão externa por pares.

\section{ETHICAL DISCLOSURES}

CONFLICTS OF INTEREST: The authors have no conflicts of interest to declare.

FINANCING SUPPORT: This work has not received any contribution, grant or scholarship.

PROVENANCE AND PEER REVIEW: Not commissioned; externally peer reviewed.

\section{REFERÊNCIAS}

1. World Health Organization. 2019 Novel Coronavirus (2019nCov): Strategic Preparedness and Response Plan. Geneva: $\mathrm{WHO} ; 2020$.

2. European Centre for Disease Prevention and Control. Guidelines for the use of non-pharmaceutical measures to delay and mitigate the impact of 2019 nCoV. Stockholm: ECDPC; 2020

3. Direção-Geral da Saúde. Pandemia de COVID-19. Plano Nacional de Preparação e Resposta à Doença por novo coronavírus (COVID-19). Lisboa: DGS; 2020.

4. Nagesh S, Chakraborty S. Saving the frontline health workforce amidst the COVID-19 crisis: Challenges and recommendations. J Glob Health. 2020;10:010345. doi: 10.7189/jogh-10010345

5. The Lancet. COVID-19: protecting health-care workers. Lancet. 2020;395:922. doi: 10.1016/S0140-6736(20)30644-9.

6. Direção-Geral da Saúde. Prevenção e Controlo de Infeção por SARS-CoV-2 (COVID-19): Equipamentos de Proteção Individual (EPI). Norma nº 007/2020 de 29/03/2020. Lisboa: DGS; 2020.

7. Sociedad Española de Urgencias de Pediatría. Recomendaciones SEUP por SARS-CoV-2 (Cuadro clínico: COVID 19). [consultado maio 2020] Disponível em: https://www.aeped. es/sites/default/files/recomendaciones_seup_covid-19_definitivo.pdf.

8. Xiao A, Tong Y, Zhang S. False-negative of RT-PCR and Prolonged Nucleic Acid Conversion in COVID-19: Rather Than Recurrence. J Med Virol. 2020 (in press). doi:101002/jmv25855.
9. European Resuscitation Council. European Resuscitation Council COVID-19 Guidelines. [consultado abril 2020] Disponível em: https:/www.erc.edu/sites/5714e77d5e615861f00f7d18/content_entry5ea884fa4c84867335e4d1ff/5ea886844c84867421e4d1ef/files/ERC_covid19_pages_section4.pdf?1588941021.

10. Direção-Geral da Saúde. COVID-19: FASE DE MITIGAÇÃO - Abordagem do Doente com Suspeita ou Infeção por SARS-CoV-2. Norma n 004/2020 de 23/03/2020 atualizada a 25/04/2020. Lisboa: DGS; 2020

11. Alexander A, De Smet A, Weiss L. Decision making in uncertain times.McKinsey Quarterly[2020-04-24]Disponívelem:http:// www.mckinsey.com/business-functions/organization/our-insights/decision-making-in-uncertain-times?cid=other-eml-alt-mip-mck\&hlkid=ecd1c6d374694fde805f4cd46b2477e$c \& h c t k y=2956465 \&$ hdpid $=057 d 6 d 6 a-767 f-4 c 6 a-a 466-7-$ b2687a89a27\#. 